\title{
Balanced ratio of plasma to packed red blood cells improves outcomes in massive transfusion: A large multicenter study
}

\author{
JIANG-CUN YANG ${ }^{1 *}$, CUI-XIANG XU ${ }^{2 *}$, YANG SUN $^{1}$, QIAN-LI DANG $^{3}$, \\ LING $\mathrm{LI}^{4}$, YONG-GANG XU ${ }^{5}$, YAO-JUN SONG ${ }^{1}$ and HONG YAN ${ }^{6 *}$ \\ ${ }^{1}$ Department of Transfusion Medicine; ${ }^{2}$ Shaanxi Provincial Center for Clinical Laboratory; Departments of ${ }^{3}$ Dermatology, \\ ${ }^{4}$ Laboratory and ${ }^{5}$ Urology, The Third Affiliated Hospital of Medical College of Xi'an Jiaotong University; \\ ${ }^{6}$ Department of Epidemiology and Health Statistics, Medical College of Xi'an Jiaotong University, \\ Xi'an, Shaanxi 710061, P.R. China
}

Received July 27, 2014; Accepted April 2, 2015

DOI: $10.3892 /$ etm.2015.2461

\begin{abstract}
Resuscitation with the early administration of plasma can improve the survival of patients undergoing surgery or trauma patients who require massive transfusion. To ascertain the optimal ratio of fresh frozen plasma (FFP) to packed red blood cells ( $\mathrm{pRBCs}$ ) in massive transfusions, the records of 1,048 patients who received a massive transfusion at 20 hospitals were retrospectively reviewed. The patients were stratified into three groups according to the ratio of FFP to pRBCs. These were the low $(<1: 2.3)$, middle (1:2.3-0.75) and high ( $\geq 1: 0.75)$ ratio groups. For $24-\mathrm{h}$ treatment, the middle FFP:pRBC ratio led to a lower mortality rate $(9.31 \%)$ compared with that in the low $(11.83 \%)$ and high $(11.44 \%)$ ratio groups $(\mathrm{P}=0.477)$. For 72 -h treatment, the middle FFP:pRBC ratio also lead to the lowest mortality rate $(7.25 \%)$, which was significantly lower than the ratios in the low $(10.39 \%)$ and high $(13.65 \%)$ ratio groups $(\mathrm{P}=0.007)$. The length of hospital stay, ICU stay, and FFP:pRBC ratio in $72 \mathrm{~h}$ were found to be significant associated with mortality. The optimal ratio of FFP to pRBCs of 1:2.3-0.75 in $72 \mathrm{~h}$ can improve the survival of patients undergoing massive transfusions.
\end{abstract}

\section{Introduction}

Hemorrhagic shock remains a leading cause of potentially preventable morbidity and mortality in severely injured

Correspondence to: Professor Hong Yan, Department of Epidemiology and Health Statistics Medical College of Xi'an Jiaotong University, 277 Yanta West Road, Xi'an, Shaanxi 710061, P.R. China

E-mail: yanhongyjc@163.com

*Contributed equally

Key words: fresh frozen plasma, packed red blood cells, surgical transfusion civilians and military personnel $(1,2)$. Although the earlier control of life-threatening hemorrhage can significantly improve patient outcomes, massive transfusion is still required and is a critical lifesaving treatment for hemorrhagic shock $(3,4)$. Massive transfusion is commonly defined as the administration of $\geq 10$ units of packed red blood cells ( $p R B C s$ ) to an individual patient or the transfusion of more than one blood volume in $24 \mathrm{~h}$ (5-9). Alternative definitions that may be more helpful in the acute situation include a $50 \%$ blood volume loss within $3 \mathrm{~h}$ or a rate of loss of $150 \mathrm{ml} / \mathrm{min}$ (5).

Severe trauma is the most common reason for massive transfusion. Massive transfusion is also frequently required as a treatment for severe hemorrhage in patients undergoing complex surgery. (3) The rapid identification of patients who may require massive transfusion is critically important as it may enable the lives of the most severely injured patients to be saved. A rational blood transfusion treatment can improve patient outcomes, but unreasonable transfusion can increase mortality in patients. Therefore, determining the optimal ratio of fresh frozen plasma (FFP) to pRBCs is a major step in delivering optimal care. A number of studies have reported that a high ratio of FFP to $\mathrm{pRBCs}$ at an early phase may reduce the mortality rate of trauma patients (10-16).

It is noteworthy that the effects of FFP to pRBCs ratios on patient outcomes in China have not yet been clearly defined. Therefore, the present retrospective study of 20 centers in China was performed. The purpose of the study was to determine the optimal ratio of FFP to pRBCs for severely bleeding patients who received massive transfusions.

\section{Materials and methods}

General information. A multicenter, retrospective analysis was performed at 20 tertiary hospitals in China. The study protocol was approved by the institutional review boards at all participating centers.

Massive transfusion. In this study, massive transfusion was defined as the receipt of $\geq 10 \mathrm{U}$ of pRBCs in the first $24 \mathrm{~h}$ of admission to the surgical operation or emergency room or the intensive care unit (ICU). 
Study population. The study population included adults (18 years and older) who presented to 20 tertiary hospitals between January 2009 and December 2010 and received a massive transfusion due to severe trauma or surgery. The severely bleeding patients undergoing surgery consisted of cardiac surgery patients, patients undergoing general surgery (for example, orthopedic, chest, general, urinary or hepatobiliary surgery or neurosurgery) and obstetric patients. Patients were excluded if they had suffered severe hemorrhage due to blood diseases, liver failure or clotting factor defects. To eliminate the bias of the delay in availability of plasma, all trauma patients who succumbed within $30 \mathrm{~min}$ of arrival to the emergency room were excluded.

Groups. The massive transfusion patients were stratified into three groups according to their receipt of low, middle and high ratios of FFP:pRBCs in 24 and $72 \mathrm{~h}$, specifically at ratios of $<1: 2.3,1: 2.3-0.75$, and $\geq 1: 0.75$. A FFP:pRBC ratio of 1-1.5:1 is reported to be required in massive transfusion (17), and a FFP:pRBC ratio of 1:1-2 is capable of correcting coagulopathy in the massive transfusion $(12,17,18)$. Therefore, a FFP:pRBC ratio of 1:1-2 is considered routine, and is included in the middle ratio group; a FFP:pRBC ratio $\geq 1: 0.75$ has a high proportion of plasma and a FFP:pRBC ratio $<1: 2.3$ has a low proportion of plasma.

Data collection. The data were collected prior to transfusion. All measurements of respiration, pulse, systolic blood pressure (SBP), body temperature, red blood cell (RBC) count, hemoglobin $(\mathrm{Hb})$ concentration, platelet (PLT) count, prothrombin time (PT), activated partial thromboplastin time (APTT), thrombin time (TT), international normalized ratio (INR), and fibrinogen (FIB) concentration were recorded as often as clinically assessed.

A database was created, and detailed information on patient demographic characteristics and clinical features were collected, including age, gender, weight, blood products, the time and date of injury and admission, mechanism of injury, time of admission to the ICU, time of surgery, and time from admission to discharge.

Mortality assessment. Dates of mortality were recorded for those that occurred between study enrollment and on or before day 30 after hospital admission. Mortality was defined as death in hospital within 30 days, prior to discharge.

Statistical analysis. Statistical analysis was conducted using SPSS version 18.0 for Windows (SPSS, Inc., Chicago, IL, USA). EpiData software, version 3.01 (Epidata Association, Odense, Denmark) was used for double data entry and data construction. Demographic characteristics and clinical features are expressed as means with standard deviations or as absolute numbers. Categorical variables were analyzed by $\chi^{2}$ tests. Continuous variables with normal distribution were analyzed by the Shapiro-Wilk test, Student's t-test or Mann-Whitney U test, as appropriate. To adjust for other risk factors, logistic regression was used. Results from logistic regression models are reported as odds ratios (OR) with 95\% confidence intervals (CI). Survival rates between patients receiving different ratios of FFP:pRBCs were estimated by the Kaplan-Meier method and the curves were analyzed using the log-rank test. A two-sided P-value $<0.05$ was considered statistically significant.

\section{Results}

Baseline characteristics of study subjects. Data were obtained from 1,048 patients who received a massive transfusion. There were no differences among all groups in gender, age, causes of massive transfusion, and the majority of the clinical features. The detailed data of baseline characteristics and clinical features of the patients are listed in Tables I and II.

Outcomes. The overall mortality rate was $10.31 \%$ (108 patients succumbed, 940 patients survived). Although the mortality rate was the lowest when patients received a 1:2.3-0.75 ratio of FFP:pRBCs in $24 \mathrm{~h}$, there were no significant differences among the groups (Table III). In a 72-h treatment period, a similar trend was observed; however, the mortality rate was significantly lower than that in the other groups when patients received a 1:2.3-0.75 ratio of FFP:pRBCs (Table III).

Kaplan-Meier survival analysis with log-rank testing was performed for calculating the cumulative probability of patient survival with different ratios of FFP:pRBCs in $24 \mathrm{~h}$ and $72 \mathrm{~h}$. The results revealed no significant differences among the groups with different ratios of FFP:pRBCs in $24 \mathrm{~h}(\mathrm{P}=0.060$; Fig. 1). However, the results highlight the superiority of a 1:2.3-0.75 ratio of FFP:pRBCs in $72 \mathrm{~h}$ with the highest probability of patient survival ( $\mathrm{P}=0.003$; Fig. 2).

Multivariate analysis for control of confounding variables. A multivariate logistic regression analysis was further performed for control of confounding variables and to determine which variables are independent predictors of in-hospital mortality. Adjustment for the confounding effects of age, gender, surgery time, weight, primary disease, length of stay, ICU stay, FFP:pRBC ratio in $24 \mathrm{~h}$ and FFP:pRBC ratio in $72 \mathrm{~h}$ was conducted. The results revealed that length of hospital stay $(\mathrm{OR}=1.113 ; 95 \% \mathrm{CI}: 1.056-1.172 ; \mathrm{P}<0.001)$, ICU stay $(\mathrm{OR}=0.315 ; 95 \% \mathrm{CI}: 0.137-0.725 ; \mathrm{P}=0.007)$ and FFP:pRBC ratio in $72 \mathrm{~h}(\mathrm{OR}=0.349,95 \% \mathrm{CI}$ : $0.232-0.523$; $\mathrm{P}<0.001)$ were significantly and independently associated with in-hospital mortality (Table IV).

\section{Discussion}

This large multicenter study, to the best of our knowledge, is the first to reveal the associations between the ratio of FFP to pRBCs and mortality in patients receiving massive transfusions in China.

The data showed that, in a total of 1,048 massive transfusion patients, 108 patients succumbed and 940 patients survived, corresponding to a mortality rate of $10.31 \%$, which is lower than that reported by other studies $30-70 \%$ (19), $19-45 \%$ (11) and 39\% (20). One reason may be that the subjects of the present study included a relatively small proportion of trauma patients.

Numerous studies have demonstrated a potential survival benefit from higher ratios of FFP to PRBCs in patients with trauma-induced coagulopathy requiring massive transfu- 
Table I. Demographic characteristics and clinical features based on FFP:pRBC ratio in $24 \mathrm{~h}$.

\begin{tabular}{|c|c|c|c|c|}
\hline \multirow[b]{2}{*}{ Variable } & \multicolumn{3}{|c|}{ Ratio } & \multirow[b]{2}{*}{ P-value } \\
\hline & $<1: 2.3$ & $1: 0.75-2.3$ & $\geq 1: 0.75$ & \\
\hline Number of patients & 186 & 591 & 271 & \\
\hline \multicolumn{5}{|l|}{ Demographics } \\
\hline Age, years & $45.8 \pm 17.2$ & $45.4 \pm 16.4$ & $43.2 \pm 17$ & $0.160^{\mathrm{a}}$ \\
\hline Male gender, $\mathrm{n}(\%)$ & $123(19.0)$ & $364(56.3)$ & $159(24.6)$ & $0.273^{\mathrm{b}}$ \\
\hline Weight, kg & $59.4 \pm 11.5$ & $58.6 \pm 11.4$ & $57.7 \pm 11.3$ & $0.365^{\mathrm{a}}$ \\
\hline \multicolumn{5}{|l|}{ Causes of massive transfusion } \\
\hline Trauma, $\mathrm{n}$ & 31 & 111 & 45 & $0.657^{\mathrm{b}}$ \\
\hline Cardiac surgery, $\mathrm{n}$ & 40 & 144 & 83 & $0.056^{\mathrm{b}}$ \\
\hline General surgery, $\mathrm{n}$ & 107 & 304 & 130 & $0.130^{\mathrm{b}}$ \\
\hline Obstetric delivery, $\mathrm{n}$ & 8 & 32 & 13 & $0.798^{\mathrm{b}}$ \\
\hline \multicolumn{5}{|l|}{ Investigations before transfusion } \\
\hline Respiration, $\mathrm{n} / \mathrm{min}$ & $20.4 \pm 3.5$ & $20.5 \pm 3.5$ & $20.4 \pm 3.9$ & $0.898^{\mathrm{a}}$ \\
\hline Pulse, $\mathrm{n} / \mathrm{min}$ & $98.7 \pm 90$ & $91.7 \pm 49.5$ & $89.9 \pm 21.1$ & $0.336^{\mathrm{a}}$ \\
\hline $\mathrm{SBP}, \mathrm{mmHg}$ & $119.7 \pm 31.5$ & $111.9 \pm 29.1$ & $110 \pm 31.2$ & $0.014^{\mathrm{a}}$ \\
\hline Temperature, ${ }^{\circ} \mathrm{C}$ & $36.6 \pm 0.9$ & $36.6 \pm 0.5$ & $36.4 \pm 0.9$ & $0.053^{\mathrm{a}}$ \\
\hline $\mathrm{RBC}, \mathrm{x} 10^{12} / 1$ & $3.9 \pm 1$ & $3.8 \pm 1$ & $3.9 \pm 1.2$ & $0.674^{\mathrm{a}}$ \\
\hline $\mathrm{Hb}, \mathrm{g} / \mathrm{l}$ & $117.8 \pm 33.2$ & $116.8 \pm 43.5$ & $115 \pm 34$ & $0.660^{\mathrm{a}}$ \\
\hline PLT, $\times 10^{9} / 1$ & $175.1 \pm 91.5$ & $180.3 \pm 95.7$ & $171.1 \pm 99.9$ & $0.304^{\mathrm{a}}$ \\
\hline $\mathrm{PT}$, sec & $13.4 \pm 4.2$ & $14.1 \pm 6.5$ & $14.3 \pm 6.6$ & $0.327^{\mathrm{a}}$ \\
\hline APTT, sec & $34.2 \pm 20.1$ & $35.6 \pm 21.6$ & $35.3 \pm 18.7$ & $0.793^{\mathrm{a}}$ \\
\hline $\mathrm{TT}, \mathrm{sec}$ & $16.4 \pm 5.3$ & $17.5 \pm 11.1$ & $17.6 \pm 8.1$ & $0.463^{\mathrm{a}}$ \\
\hline INR & $1.2 \pm 0.5$ & $1.3 \pm 1.8$ & $1.2 \pm 1$ & $0.423^{\mathrm{a}}$ \\
\hline FIB $(g / l)$ & $16.1 \pm 65.5$ & $9.5 \pm 39.6$ & $11.7 \pm 46.1$ & $0.356^{\mathrm{a}}$ \\
\hline \multicolumn{5}{|l|}{ Management } \\
\hline Length of hospital stay, days & $27.8 \pm 19.2$ & $31.3 \pm 26.3$ & $27.7 \pm 21.1$ & $0.063^{\mathrm{a}}$ \\
\hline Length of ICU stay, days & $7.8 \pm 14$ & $7.7 \pm 11$ & $11.5 \pm 42.1$ & $0.478^{\mathrm{a}}$ \\
\hline Surgery time, $\mathrm{h}$ & $3.48 \pm 3.7$ & $3.85 \pm 3.05$ & $3.45 \pm 3.45$ & $0.313^{\mathrm{a}}$ \\
\hline $\mathrm{pRBC}$ in $24 \mathrm{~h}, \mathrm{U}$ & 16 & 19 & 20 & $0.107^{\mathrm{b}}$ \\
\hline FFP in $24 \mathrm{~h}, \mathrm{U}$ & 14 & 12 & 15 & $0.139^{\mathrm{b}}$ \\
\hline PLT in $24 \mathrm{~h}, \mathrm{U}$ & 7 & 10 & 4 & $0.803^{\mathrm{b}}$ \\
\hline $\mathrm{pRBC}$ in $72 \mathrm{~h}, \mathrm{U}$ & 16 & 18 & 21 & $0.006^{\mathrm{b}}$ \\
\hline FFP in $72 \mathrm{~h}, \mathrm{U}$ & 14 & 12 & 14 & $0.256^{\mathrm{b}}$ \\
\hline PLT in $72 \mathrm{~h}, \mathrm{U}$ & 10 & 10 & 3 & $0.734^{\mathrm{b}}$ \\
\hline
\end{tabular}

Values are mean \pm standard deviation, unless otherwise indicated. FFP, fresh frozen plasma; pRBC, packed red blood cell; SBP, systolic blood pressure; RBC, red blood cell count; Hb, hemoglobin concentration; PLT, platelet count; PT, prothrombin time; APTT, activated partial thromboplastin time; TT, thrombin time; INR, international normalized ratio; FIB, fibrinogen concentration; ICU, intensive care unit. ${ }^{\mathrm{a} D e t e r m i n e d}$ using analysis of variance. ${ }^{b}$ Determined using Kruskall-Wallis test.

sions (7,21-26). Borgman et al (13) reported that the ratio of blood products transfused affects mortality in patients receiving massive transfusions following a retrospective chart review of 246 massive transfusion patients. In the review, it was found that overall mortality rates in the low (1:8), medium (1:2.5), and high (1:1.4) plasma to $\mathrm{RBC}$ ratio groups were 65, 34 and 19\%, respectively. Upon logistic regression, a high 1:1.4 plasma to $\mathrm{RBC}$ ratio was found to be independently associated with improved survival. The authors suggested that massive transfusion protocols should utilize a 1:1 ratio of FFP to pRBCs for all patients who are hypocoagulable with traumatic injuries. Murad et al (16) performed a meta-analysis and confirmed that a ratio of FFP to $\mathrm{pRBCs}$ of $>1: 3$ was associated with reduced mortality in massive transfusion patients.

In the current study, a retrospective analysis was performed of 1,048 patients who received $\geq 10 \mathrm{U}$ of pRBCs in the first $24 \mathrm{~h}$ of admission. The patients were divided into three groups according to their ratio of FFP to pRBCs, namely the low $(<1: 2.3)$, medium (1:2.3-0.75), and high ( $\geq 1: 0.75)$ ratio groups. It was found that the mortality rate when a ratio of 1:2.3-0.75 
Table II. Demographic characteristics and clinical features based on FFP:pRBC ratio in $72 \mathrm{~h}$.

\begin{tabular}{|c|c|c|c|c|}
\hline \multirow[b]{2}{*}{ Variable } & \multicolumn{3}{|c|}{ Ratio } & \multirow[b]{2}{*}{ P-value } \\
\hline & $<1: 2.3$ & $1: 0.75-2.3$ & $\geq 1: 0.75$ & \\
\hline Number of patients & 154 & 469 & 425 & \\
\hline \multicolumn{5}{|l|}{ Demographics } \\
\hline Age, years & $46.1 \pm 16.4$ & $44.4 \pm 16.6$ & $45 \pm 17.0$ & $0.576^{\mathrm{a}}$ \\
\hline Male gender, $\mathrm{n}(\%)$ & $100(15.5)$ & $269(41.6)$ & $277(42.9)$ & $0.038^{\mathrm{b}}$ \\
\hline Weight, kg & $60.2 \pm 10.9$ & $59.1 \pm 10.8$ & $57.4 \pm 12.0$ & $0.030^{\mathrm{a}}$ \\
\hline \multicolumn{5}{|l|}{ Causes of massive transfusion } \\
\hline Trauma, $\mathrm{n}$ & 28 & 89 & 70 & $0.621^{\mathrm{b}}$ \\
\hline Cardiac surgery, $\mathrm{n}$ & 31 & 98 & 138 & $<0.001^{\mathrm{b}}$ \\
\hline General surgery, $\mathrm{n}$ & 89 & 251 & 201 & $0.046^{\mathrm{b}}$ \\
\hline Obstetric delivery, $\mathrm{n}$ & 6 & 31 & 16 & $0.122^{\mathrm{b}}$ \\
\hline \multicolumn{5}{|l|}{ Investigations before transfusion } \\
\hline Respiration, $\mathrm{n} / \mathrm{min}$ & $20.3 \pm 2.5$ & $20.6 \pm 3.9$ & $20.4 \pm 3.6$ & $0.668^{\mathrm{a}}$ \\
\hline Pulse, $\mathrm{n} / \mathrm{min}$ & $95.6 \pm 67.8$ & $90.7 \pm 43.6$ & $93.4 \pm 59.9$ & $0.660^{\mathrm{a}}$ \\
\hline $\mathrm{SBP}, \mathrm{mmHg}$ & $122.6 \pm 32$ & $112.5 \pm 27$ & $108.8 \pm 32.3$ & $<0.001^{\mathrm{a}}$ \\
\hline Temperature, ${ }^{\circ} \mathrm{C}$ & $36.6 \pm 0.9$ & $36.6 \pm 0.5$ & $36.5 \pm 0.8$ & $0.210^{\mathrm{a}}$ \\
\hline $\mathrm{RBC}, \mathrm{x} 10^{12} / 1$ & $3.9 \pm 1.0$ & $3.8 \pm 1.0$ & $3.9 \pm 1.2$ & $0.233^{\mathrm{a}}$ \\
\hline $\mathrm{Hb}, \mathrm{g} / \mathrm{l}$ & $3.8 \pm 1.1$ & $120.1 \pm 34$ & $117.4 \pm 50.2$ & $0.698^{\mathrm{a}}$ \\
\hline PLT, $\times 10^{9} / 1$ & $179.2 \pm 96.1$ & $180.9 \pm 98.7$ & $167.1 \pm 100.2$ & $0.169^{\mathrm{a}}$ \\
\hline $\mathrm{PT}$, sec & $13.7 \pm 5$ & $14.3 \pm 5.5$ & $14.1 \pm 6.5$ & $0.653^{\mathrm{a}}$ \\
\hline APTT, sec & $35.6 \pm 23.4$ & $35.9 \pm 15.3$ & $37.2 \pm 33.1$ & $0.801^{\mathrm{a}}$ \\
\hline TT, sec & $17 \pm 5.8$ & $17.3 \pm 6.0$ & $18.1 \pm 8.8$ & $0.312^{\mathrm{a}}$ \\
\hline INR & $1.2 \pm 0.6$ & $1.3 \pm 1.4$ & $1.2 \pm 0.4$ & $0.323^{\mathrm{a}}$ \\
\hline FIB (g/l) & $12.6 \pm 27.1$ & $7.4 \pm 29.9$ & $15.3 \pm 67.9$ & $0.163^{\mathrm{a}}$ \\
\hline \multicolumn{5}{|l|}{ Management } \\
\hline Length of hospital stay, days & $29.6 \pm 25.9$ & $31.1 \pm 27.2$ & $28.3 \pm 18.6$ & $0.222^{\mathrm{a}}$ \\
\hline Length of ICU stay, days & $9.2 \pm 14.6$ & $7.5 \pm 11.7$ & $10.2 \pm 35.7$ & $0.649^{\mathrm{a}}$ \\
\hline Surgery time, $\mathrm{h}$ & $3.7 \pm 3.9$ & $3.8 \pm 4.0$ & $3.5 \pm 4.0$ & $0.508^{\mathrm{a}}$ \\
\hline $\mathrm{pRBC}$ in $24 \mathrm{~h}, \mathrm{U}$ & 16 & 19 & 20 & $0.055^{\mathrm{b}}$ \\
\hline FFP in $24 \mathrm{~h}, \mathrm{U}$ & 14 & 12 & 15 & $0.567^{\mathrm{b}}$ \\
\hline PLT in $24 \mathrm{~h}, \mathrm{U}$ & 8 & 10 & 4 & $0.737^{\mathrm{b}}$ \\
\hline $\mathrm{pRBC}$ in $72 \mathrm{~h}, \mathrm{U}$ & 16 & 18 & 21 & $0.006^{\mathrm{b}}$ \\
\hline FFP in $72 \mathrm{~h}, \mathrm{U}$ & 14 & 12 & 14 & $0.256^{\mathrm{b}}$ \\
\hline PLT in $72 \mathrm{~h}, \mathrm{U}$ & 10 & 10 & 5 & $0.734^{\mathrm{b}}$ \\
\hline
\end{tabular}

Values are mean \pm standard deviation, unless otherwise indicated. FFP, fresh frozen plasma; pRBC, packed red blood cell; ; SBP, systolic blood pressure; RBC, red blood cell count; Hb, hemoglobin concentration; PLT, platelet count; PT, prothrombin time; APTT, activated partial thromboplastin time; TT, thrombin time; INR, international normalized ratio; FIB, fibrinogen concentration; ICU, intensive care unit. ${ }^{\mathrm{a} D e t e r m i n e d}$ using analysis of variance. ${ }^{b}$ Determined using Kruskall-Wallis test.

was used was the lowest (9.3\%). Above and below this ratio, the mortality rate was higher, but the difference between groups did not reach statistical significance.

An analysis of the effect on survival of the ratio of FFP to $\mathrm{pRBCs}$ in massive transfusion patients in the first $72 \mathrm{~h}$ of admission was also performed. The results indicated that the mortality rate with a 1:2.3-0.75 FFP:pRBC ratio was the lowest (7.25\%); above and below this ratio, the mortality rates were higher (13.65 and $10.39 \%$, respectively). The mortality rate with a high FFP level was particularly high. Therefore, a suitable ratio of FFP to pRBCs (1:2.3-0.75) can improve the survival rate of patients with massive transfusion in the first $72 \mathrm{~h}$; however, transfusion with a high FFP content increased mortality. The findings of the present study were in contrast to those of previous studies $(13,16,27)$, which suggested that transfusion with a high FFP transfusion can improve survival. The factors leading to the divergence require further study.

Whether the results were influenced by confounding factors was also investigated. The results of multivariate analysis demonstrated that length of stay, ICU stay and FFP:pRBC 
Table III. Mortality rates according to the FFP:pRBC ratio in 24 and $72 \mathrm{~h}$.

\begin{tabular}{lcccc}
\hline & \multicolumn{4}{c}{ Ratio } \\
\cline { 2 - 5 } Patient outcome & Total & $<1: 2.3$ & $1: 0.75-2.3$ & $\geq 1: 0.75$ \\
\hline At 24 h, n (\%) & & & & \\
Mortality & $108(10.31)$ & $22(11.83)$ & $55(9.31)$ & $31(11.44)$ \\
Survival & $940(89.69)$ & $164(88.17)$ & $536(90.69)$ & $240(88.56)$ \\
Total & $1,048(100)$ & $186(100)$ & $591(100)$ & $271(100)$ \\
At 72 h, n (\%) & & & & \\
Mortality & $108(10.31)$ & $16(10.39)$ & $34(7.25)$ & $58(13.65)$ \\
Survival & $940(89.69)$ & $138(89.61)$ & $435(92.75)$ & $367(86.35)$ \\
Total & $1,048(100)$ & $154(100)$ & $469(100)$ & $425(100)$ \\
\hline
\end{tabular}

an the first 24 and $72 \mathrm{~h}$ of admission, comparison of mortality between different ratios of FFP to PRBCs. FFP, fresh frozen plasma; pRBC, packed red blood cell.

Table IV. Multivariate analysis for control of confounding variables.

\begin{tabular}{|c|c|c|c|c|c|}
\hline Variable $^{a}$ & $\beta$ & SE & P-value & Odds ratio & $95 \% \mathrm{CI}$ \\
\hline Length of hospital stay & 0.107 & 0.027 & 0.000 & 1.113 & $1.056-1.172$ \\
\hline ICU stay & -1.155 & 0.425 & 0.007 & 0.315 & $0.137-0.725$ \\
\hline 72-h ratio of FFP:pRBC & -1.054 & 0.207 & 0.000 & 0.349 & $0.232-0.523$ \\
\hline Constant & 3.518 & 0.75 & 0.000 & 33.734 & 1 \\
\hline
\end{tabular}

${ }^{a}$ The following variables were considered as confounding effects: age, gender, duration of surgery, weight, primary disease, length of hospital stay, ICU stay, FFP:pRBC ratio in $24 \mathrm{~h}$ and FFP:pRBC ratio in $72 \mathrm{~h}$. ICU, intensive care unit; FFP, fresh frozen plasma; pRBC, packed red blood cell; SE, standard error; CI, confidence interval.

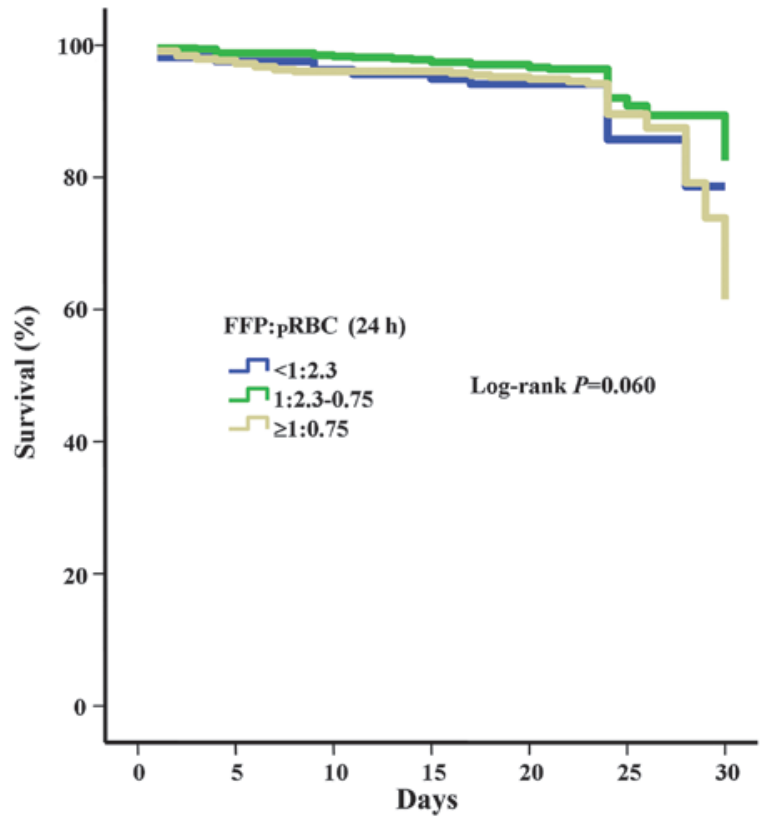

Figure 1. Mortality rates grouped by different FFP:pRBC ratios in $24 \mathrm{~h}$ are presented as a Kaplan-Meier survival plot. There were no significant differences in mortality among the three groups $(\mathrm{P}=0.060)$. However, for the middle FFP:pRBC (1:2.3-0.75) and high FFP:pRBC ( $\geq 1: 0.75)$ ratio groups, the mortality rates were the lowest and highest, respectively. FFP, fresh frozen plasma; pRBC, packed red blood cell.

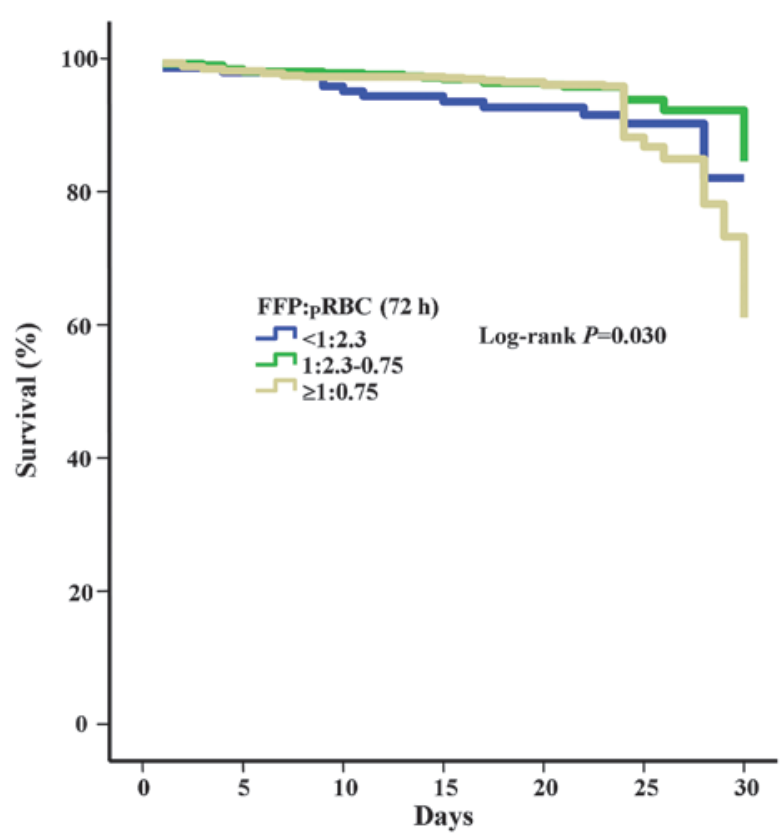

Figure 2. Mortality rates grouped by different FFP:pRBC ratios in $72 \mathrm{~h}$ are presented as a Kaplan-Meier survival plot. There were significant differences in mortality among the three groups $(\mathrm{P}=0.003)$. The middle ratio group (FFP:pRBC ratio, 1:2.3-0.75) had the lowest mortality rate and the high ratio group (FFP:pRBC ratio, $\geq 1: 0.75$ ) had the highest mortality rate. FFP, fresh frozen plasma; pRBC, packed red blood cell. 
ratio in $72 \mathrm{~h}$ were significantly and independently associated with in-hospital mortality. By contrast, Scalea et al (28) found that the ratio of FFP to pRBCs was not an independent risk factors for in-hospital mortality.

In conclusion, to the best of our knowledge, this study is the first retrospective analysis of the effect of the ratio of FFP to pRBCs on survival in a large multicenter population. The data demonstrated that the optimal ratio of FFP to pRBCs was 1:2.3-0.75 in massive transfusion patients in the first $72 \mathrm{~h}$ of admission. The optimal ratio of FFP to pRBCs was also found to be 1:2.3-0.75 in massive transfusion patients in the first $24 \mathrm{~h}$ of admission, but this was not statistically significant. Transfusion with a high ratio of FFP to pRBCs in $72 \mathrm{~h}$ is an independent risk factor for in-hospital mortality.

\section{Acknowledgements}

The authors thank collaborators from the other 19 centers participating in this study: Shi-Jie Mu, Ai-Jun Xia and Xian-Qin Zhang from Xijing Hospital, the Fourth Military Medical University (Xi'an, China); Dai-Yu Li from Affiliated Hospital of Luzhou Medical College (Luzhou, China); Shu-Min Zhao from Xinang Southwest Hospital, the Third Military Medical University (Chongqing, China); Wei Jiao from the People's Hospital of Zhuang Autonomous Region (Nanning, China); Li Tong from First Affiliated Hospital of Kunming Medical University (Kunming, China); Qing-Bao Meng from Shenzhen People's Hospital (Shenzhen, China); Jie Li from the Fourth Clinical Medical College of Hebei Medical University (Shijiazhuang, China); Shi-Ming Yang from Tangdu Hospital, the Fourth Military Medical University (Xi'an, China); Suo-Liang Yao from Xi'an Hong Hui Hospital (Xi'an, China); Bi-Juan Li from Xiangya Hospital Center of South University (Changsha, China); Qiu-Shi Wang from Shengjing Hospital of China Medical University (Chenyang, China); Cui-Ying Li from General Hospital of Chengdu Military Region (Chengdu, China); Mei-Ning Han from the Second Affiliated Hospital of Medical College of Xi'an Jiaotong University (Xi'an, China); Zhi-Xi Hu from Yan'an University Affiliated Hospital (Yan'an, China); Jin-Shan Jiao from the First Affiliated Hospital of Shanxi Medical University (Taiyuan, China); Xian-Ping Lv from the First Affiliated Hospital of Zhengzhou University (Zhengzhou, China); Yan-Li Bai from Xi'an Central Hospital (Xi'an, China); Xiao-Xia Shi from Xianyang 215 Hospital (Xianyang, China); and Fang-Xiang Chen from Daping Hospital, the Third Military Medical University (Chongqing, China).

\section{References}

1. MacLeod J, Lynn M, McKenney MG, Cohn SM and Murtha M Early coagulopathy predicts mortality in trauma. J Trauma 55 39-44, 2003.

2. Teixeira PG, Inaba K, Hadjizacharia P, et al: Preventable or potentially preventable mortality at a mature trauma center. J Trauma 63: 1338-1346, 2007.

3. Sihler KC and Napolitano LM: Massive transfusion new insights. Chest 136: 1654-1667, 2009.

4. Sihler KC and Napolitano LM: Complications of massive transfusion. Chest 137: 209-220, 2010.
5. Stainsby D, MacLennan S, Thomas D, Isaac J and Hamilton PJ: Guidelines on the management of massive blood loss. $\mathrm{Br}$ J Haematol 135: 634-641, 2006.

6. Hewitt PE and Machin SJ: ABC of transfusion. Massive blood transfusion. BMJ 300: 107-109, 1990.

7. Malone DL, Hess JR and Fingerhut A: Massive transfusion practices around the globe and a suggestion for a common massive transfusion protocol. J Trauma 60 (6 Suppl): S91-S96, 2006.

8. Kozek-Langenecker S: Management of massive operative blood loss. Minerva Anestesiol 73: 401-415, 2007.

9. Schuster KM, Davis KA, Lui FY, Maerz LL and Kaplan LJ: The status of massive transfusion protocols in United States trauma centers: massive transfusion or massive confusion? Transfusion 50: 1545-1551, 2010.

10. Zink KA, Sambasivan CN, Holcomb JB, Chisholm G and Schreiber MA: A high ratio of plasma and platelets to packed red blood cells in the first $6 \mathrm{~h}$ of massive transfusion improves outcomes in a large multicenter study. Am J Surg 197: 565-570, 2009.

11. Riskin DJ, Tsai TC, Riskin L, et al: Massive transfusion protocols: the role of aggressive resuscitation versus product ratio in mortality reduction. J Am Coll Surg 209: 198-205, 2009.

12. Ho AM, Dion PW, Yeung JH, et al: Fresh-frozen plasma transfusion strategy in trauma with massive and ongoing bleeding. Common (sense) and sensibility. Resuscitation 81: 1079-1081, 2010.

13. Borgman MA, Spinella PC, Perkins JG, et al: The ratio of blood products transfused affects mortality in patients receiving massive transfusions at a combat support hospital. J Trauma 63: 805-813, 2007.

14. Stansbury LG, Dutton RP, Stein DM, et al: Controversy in trauma resuscitation: do ratios of plasma to red blood cells matter? Transfus Med Rev 23: 255-265, 2009.

15. Peiniger S, Nienaber U, Lefering R, et al: Balanced massive transfusion ratios in multiple injury patients with traumatic brain injury. Crit Care 15: R68, 2011.

16. Murad MH, Stubbs JR, Gandhi MJ, et al: The effect of plasma transfusion on morbidity and mortality: a systematic review and meta-analysis. Transfusion 50: 1370-1383, 2010.

17. Ho AM, Dion PW, Cheng CA, et al: A mathematical model for fresh frozen plasma transfusion strategies during major trauma resuscitation with ongoing hemorrhage. Can J Surg 48: 470-478, 2005.

18. Yoon S, Park AJ and Kim HO: Clinical observation study of massive blood transfusion in a tertiary care hospital in Korea. Yonsei Med J 52: 469-475, 2011.

19. Cinat ME, Wallace WC, Nastanski F, et al: Improved survival following massive transfusion in patients who have undergone trauma. Arch Surg 134: 964-968, 1999.

20. Como JJ, Dutton RP, Scalea TM, Edelman BB and Hess JR: Blood transfusion rates in the care of acute trauma. Transfusion 44: 809-813, 2004.

21. Hirshberg A, Dugas M, Banez EI, et al: Minimizing dilutional coagulopathy in exsanguinating hemorrhage: a computer simulation. J Trauma 54: 454-463, 2003.

22. Johansson PI and Stensballe J: Effect of haemostatic control resuscitation on mortality in massively bleeding patients: a before and after study. Vox Sang 96: 111-118, 2009.

23. Duchesne JC, Hunt JP, Wahl G, et al: Review of current blood transfusions strategies in a mature level I trauma center: were we wrong for the last 60 years? J Trauma 65: 272-276, 2008.

24. Jansen JO, Thomas R, Loudon MA and Brooks A: Damage control resuscitation for patients with major trauma. BMJ 338: b1778, 2009.

25. Holcomb JB, Wade CE, Michalek JE, et al: Increased plasma and platelet to red blood cell ratios improves outcome in 466 massively transfused civilian trauma patients. Ann Surg 248: 447-458, 2008.

26. Kor DJ, Stubbs JR and Gajic O: Perioperative coagulation management-fresh frozen plasma. Best Pract Res Clin Anaesthesiol 24: 51-64, 2010.

27. Spinella PC, Perkins JG, Grathwohl KW, et al: Effect of plasma and red blood cell transfusions on survival in patients with combat related traumatic injuries. J Trauma 64 (2 Suppl): S69-S78, 2008.

28. Scalea TM, Bochicchio KM, Lumpkins K, et al: Early aggressive use of fresh frozen plasma not improve outcome in critically injured trauma patients. Ann Surg 248: 578-584, 2008. 